\title{
Landscape Degradation and Restoration — A Planning Approach
}

\author{
P. M. Venodha
}

\begin{abstract}
Ecology is more related to landscape planning in which public spaces around the future needs of a region is designed. Nature conservation sites receive protection through planning processes. There are also conservation policies, which are implemented through planning processes. Planning processes related to ecological assessments are considered as the best practice which requires planning permission to undertake construction projects. In terms of conserving nature, planning plays a significant role in creating traffic free routes, construction that is significant area of habitats, proposal on protected areas, proposal on protected species and habitats, landscape considerations, proposal to enhance ecology and in case done insensitively it will negative impacts on nature. Habitat survey is considered as the desk study to identify nature conservation sites, habitats along routes, record of notable and protected species. Habitat survey is helpful in order to plan project budgets and timeframe.
\end{abstract}

Index Terms-Depuration, immersion, interdisciplinary, recreations, unprecedented.

\section{INTRODUCTION}

Terrestrial and water ecosystems are complex and perfectly organized natural

"Factories" that produce all that is required for life on Earth and to cover man's basic requirements: food, fibers, water. Some of these functions of the ecosystems are essential to man, such as air and water depuration, climate control, the nutrient cycle, soil fertility [1]. In addition, some ecosystems (beaches, woods, lakes, high mountains, secluded valleys) are our ideal places for recreation, tourism and meditation, so we can say that the ecosystems have permitted our society and economy to develop [2]. 50\% of the world's population is still engaged in farming, forestry and fishing. This proportion becomes $70 \%$ if we take the sub-Sahara, Asian and Pacific countries alone [3], [4].

$25 \%$ of the world's countries have economies that still depend, almost entirely, on the sectors above. Farming alone produces 1.3 trillion dollars of food and fibers a year [4].

\section{DATA AND METHODOLOGY}

\section{A. Data}

The photographs have been taken so as to support the observations. The impacts of human activities on the area

Manuscript received February 27, 2015; revised June 1, 2015. This work was supported in part by the Department of planning and architecture under NIT, Bhopal.

P. M. Venodha is with the National Institute of Technology, Bhopal, India (e-mail: venodha3110@gmail.com). have been also analyzed.

\section{B. Main Objective}

The main objective behind this study was to understand the ecosystems of areas nearby water reservoirs. To understand the nature and functions of these ecosystems studies were done in Bhopal. Though Bhopal is well famous for its numerous lakes, rapid urbanization in the capital of Madhya Pradesh is destroying the natural environment of these lakes [5]-[7]. Thus, the impacts of human activities on the nature have been also analyzed in the study and possible proposals and suggestions are given in order to optimize both nature conservation and urbanization.

\section{Methodology}

The area near Kaliasot Dam has been observed by a team of nine members on January 17, 2015 in the morning from 6:00 am to 11:00 am. The existing flora and the fauna and their interaction with the nature have been also observed (see Fig. 1 - Fig. 15).

\section{1) Case study: Kaliasot dam}

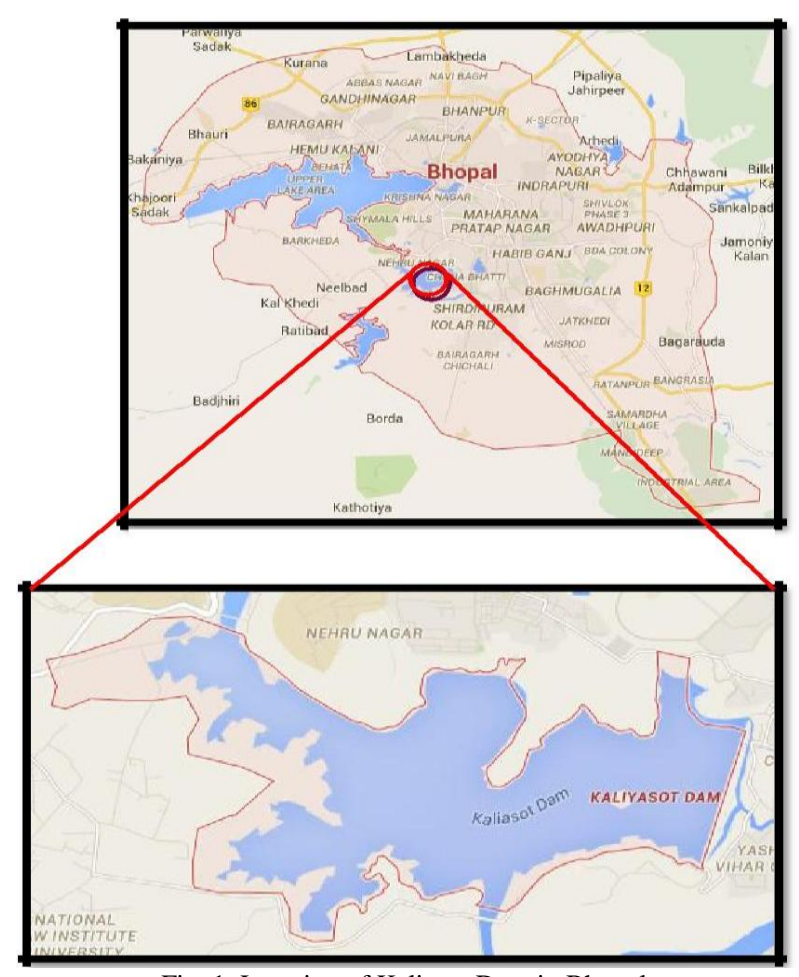

Fig. 1. Location of Kaliasot Dam in Bhopal.

The Kaliyasot Dam is situated at Bhopal, the capital city of Madhya Pradesh, is situated at 23012"3' N latitude and 770 24"29’ E longitude. Kaliyasot Dam, being, a significant source of water supply, it is one of the important feature of the city. It is basically a storage reservoir, near Chuna Bhatti 
Village, of the Kaliasot River which is a tributary of river Betwa. This dam was initially constructed for irrigational purposes and it still serves as the second source of water supply for 10,425 hectare agricultural land of Bhopal as well as Raisen district of the state. Its hindmost site is the downstream of the Bhadbhada spill gates of the Upper Lake. The dam has derived its name from the name of KalyanStrote, the one of the minister of Raja Bhoj, who had developed spillway of Upper Lake.

\section{2) Objective of case study}

The main objective of the study was to observe the various activities that occur in the region. Be it flora, fauna or human activities, everything has a prominent effect on the ecosystem of the dam. Recently Kaliasot Dam has been facing disturbing problems mostly due to various human activities that has affected the flora and fauna of the region and hence hindering the ecosystem of the area. Water is being polluted at an alarming rate and no. of birds and animals that stick to the area is decreasing. In spite of several efforts by National Green Tribunal (NGT) to conserve the Kaliasot River belt, it has shown little results [8]. Our study also aims to come up with counter-measures that will improve the ecosystem of the area and hence will merge with the nature for the better end [9], [10].

\section{OBSERVATION}

\section{A. The Kaliasot Ecosystem}

The Kaliasot reservoir is considered as a source of productive water body because of its moderate nature of water (Malik, Pachori, \& Dubey, 2014). It even acts as one of the major source of water for irrigational purposes of Bhopal as well as Raisen District (Kataria \& Singh, 2008). Hence, the freshwater ecosystem of Kaliasot has a large bio-diversity of flora and fauna [11], [12].

\section{DIVERSITY IN FLORA}

A. Algae

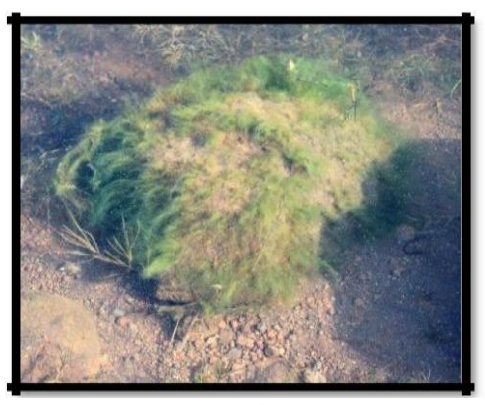

Fig. 2. Algae growing under water.

Algae are considered to be the most common flora found around any water bodies or marshy lands. The scenario of Kaliasot reservoir is no different. Green algae are found in abundance, especially on the shores.

1) Aak (Calotropis gigantean)

Calotropis gigantean, commonly known as Aak in Madhya Pradesh (India), is a large shrub. It generally grows
Approximately 4 meters (13 feet) in height. It can be usually found in Asian countries like Cambodia, Indonesia, Malaysia, Philippines, Thailand, Sri Lanka, India, China and Pakistan. It has clusters of waxy flowers that are either white or lavender in color. The plant has oval, light green leaves and milky stem.

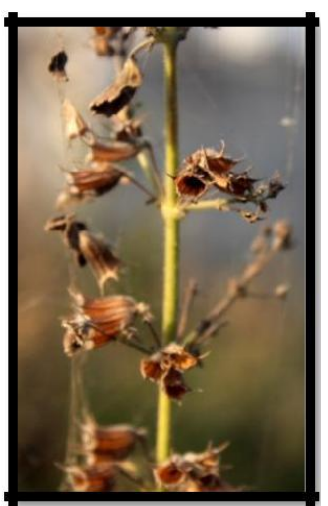

Fig. 3. Aak (calotropis gigantean)

\section{2) Satawar (Asparagus racemosus)}

Asparagus racemosus, known as Satawar in India, is a species of asparagus commonly found in Nepal and India, especially in the Himalayas. They generally are one to two meters tall and preferably grow in gravelly, rocky soils. Due to its multiple uses, the demand for Asparagus racemosus is constantly on the rise. Due to destructive harvesting, combined with habitat destruction, and deforestation, the plant is now considered "endangered" in its natural habitat.

3) Gokhroo (Xanthium indicum)

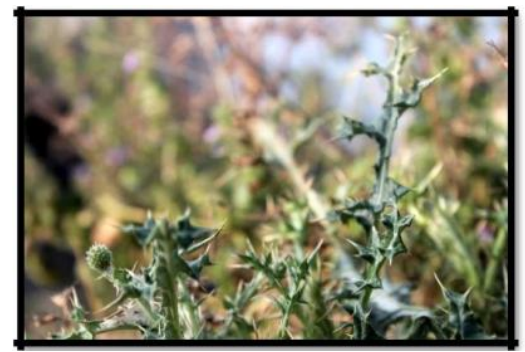

Fig. 4. Gokhroo (Xanthium indicum).

Xanthium strumarium, also known as Gokhroo, is a species of annual plants. It belongs to the Asteraceae family. The origin of this plant is believed to be in North America. Later, it has been extensively naturalized elsewhere.

4) Marod phalli (Helicteres isor)

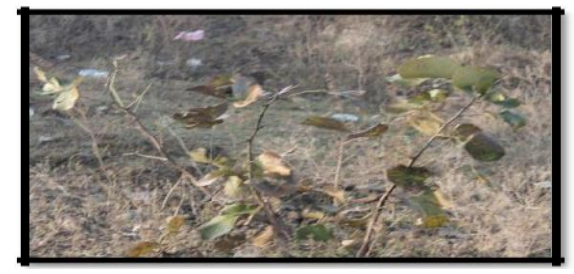

Fig. 5. Marod phalli (Helicteres isora)

Helicteres isora, known as Marod phalli in Hindi, is a species of small tree or large shrub found mostly in Asia including India, South china, Malay Peninsula, Java and Saudi Arabia. They are also found in Australia. Fibers from 
the bark of these trees are used to make rope. They act as habitat for many butterflies and other insects.

5) Lichen

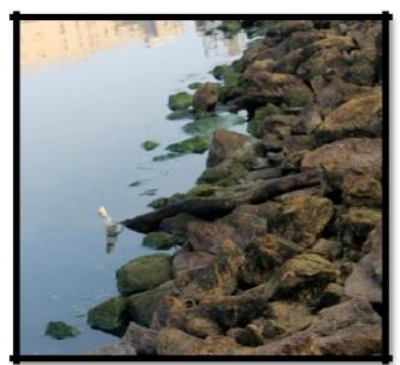

Fig. 6. Lichens growing on the rocks.

Lichens have grown in abundance near the reservoir as they are adaptable to any kind of climatic conditions. They can even survive in some of the most extreme environments on Earth. They generally grow in abundance bark, leaves, and branches. They also grow on bare rock, walls, gravestones, roofs, exposed soil surfaces. They can even live inside solid rock growing between the grains, and in the soil as a part of a biological soil crust in arid habitats such as deserts.

\section{B. Birds}

\section{1) Indian roller}

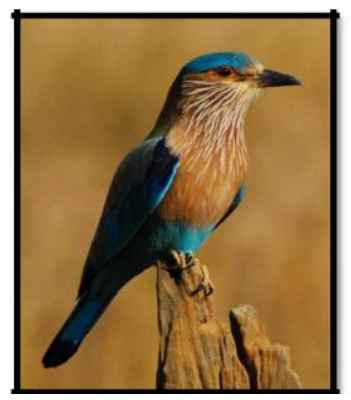

Fig. 7. Indian rolller.

The Indian roller is one of the members of the roller family of birds. They are very commonly seen perched along roadside trees, wires, open grassland and scrub forest habitats. These birds are usually seen perched on prominent bare trees or wires. They descend to the ground to capture their prey which may include insects, arachnids, small reptiles and small snakes and amphibians.

2) Grey francolin

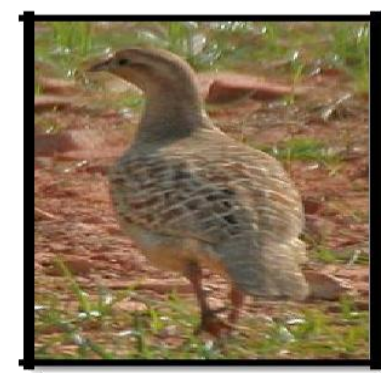

Fig. 8. Grey francolin.

It is the most abundant and wide spread of the species. They are often seen at the roadside. A plump, fast running bird which keeps to the undergrowth, the francolin only flies when disturbed.

\section{3) House sparrow}

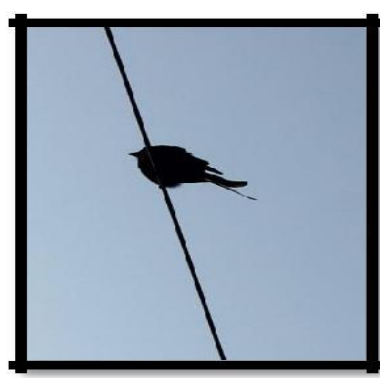

Fig. 9. House sparrow.

The house sparrow is a bird of the sparrow family Passeridae, found in most parts of the world. Females and young birds are colored pale brown and grey, and males have brighter black, white, and brown markings.

\section{4) Small blue kingfisher}

Small blue kingfisher is a Resident bird found in India. They are commonly found in Jheels, wetlands, dams.

5) Heron

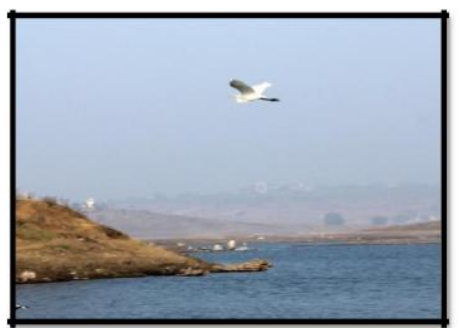

Fig. 10. Heron.

The herons are carnivorous. The members of this family are mostly associated with wetlands and water, and feed on a variety of live aquatic prey.

6) Indian robin

It is the muscicapidae family's bird. These birds are commonly found in open scrub areas and commonly seen running along the ground or perching or low thorny shrubs and rocks.

7) House crow

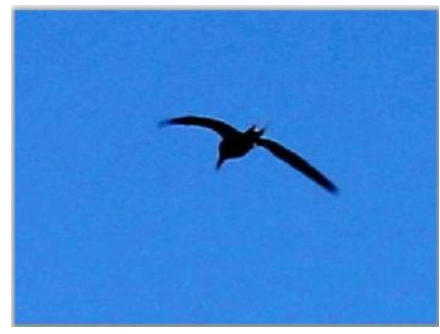

Fig. 11. House crow.

The house crow is also called Indian, Grey necked, Ceylon or Colombo crow. They are the member of crow family which is Asian origin but now found in many parts of the world. House crow largely feed on large refuse around human habitation, small reptiles and other animals such as insects and other small invertebrates, eggs, nestling, grain and fruits.

\section{Human Intervention}

Though the reservoirs were constructed at places away from the human settlements of the city, but due to 
unprecedented expansion in population and city limits of Bhopal in past few decades, these reservoirs have come well within the urban sprawl. Hence, both the aquatic ecosystem as well as terrestrial ecosystem is affected by the inadmissible human activities [13], [14].

\section{1) Disposal of waste}

The disposal of municipal liquid and solid waste into the water has led to the contamination of water. This has polluted the water to a large extent. Also the disposal of waste from the nearby buildings directly into the water has also led to the water pollution [15]. The dumping of untreated waste or throwing of polythenes, papers and waste products by the visitors is the major problem in this area.

\section{2) Water contamination}

Human intervention in the environment causes water contamination and jeopardizes the supply and flow of clean, natural drinking water. Human activities such as waste disposal from residential, commercial and industrial places all contaminate water bodies. The net effect of the contamination has been the death and reduction in diversity of marine life and scarcity of clean water [16].

\section{3) Place of recreation}

Area around a water body is also a place for different recreations. Because these places provide calm environment, clean surrounding, fresh air and many more which attract people at these places especially in morning hours. Environment around a water body is favorable throughout the day hence also preferred for recreation at different hours also like in evening. In morning and evening hours environment around these bodies attracts people for health related activities like morning walk, yoga etc. Some water bodies which are big enough also entertain people with different water sports and boating etc [17], [18].

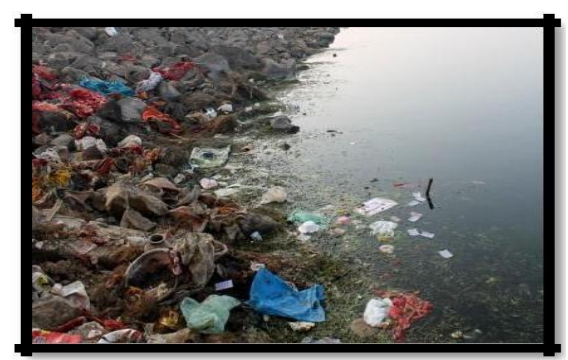

Fig. 12. Part of idols on the shores.

\section{4) Overfishing}

The water element of the environment has also suffered from exploitation when humans overfish or aggressively hunt species for their own purposes. Due to this many species in the marine life are facing unprecedented population declines . Overfishing can deplete biological diversity by causing extinctions.

\section{5) Origin of other activities}

As all these places attract large number of people some vendors found it appropriate place for some shops especially of food items. This results in origination of some small streets with small shops of different items. On one side this all is helpful for vendors as well as people visiting to these places on the other hand these shops disturbs environment of these places. As these are small shops of especially food items or other eatable items people use to throw wrappers around and these vendors also makes surrounding dirty by some of their activities [19]-[21].

\section{6) Idol immersion}

Religious ceremonies are also responsible for the water pollution at Kaliasot. Immersion of idols of god into the river and the other religious rituals during that time has also led to the contamination of water.

\section{Proposals/Suggestions}

Without making people aware of the environmental and economic importance of their local water bodies and, harmful impacts of polluting and destroying these water bodies, it is almost impossible to protect our water bodies [22]. If people can be made aware of all these then automatically they will contribute in protecting their local water bodies and the law can be easily implemented in the society [23].

- Providing dustbin near to the area where people come for recreation purpose.

- Imposing ban on immersion of idols inside lake by people during Ganpati festival.

- Providing relevant sign boards to avoid pollution in the area.

- Prohibiting plastic and polythene in that area.

- Making people aware about the effects of polluted water bodies by various kinds of events.

- Kaliyasot Morning Walker Association can make proper management of the area.

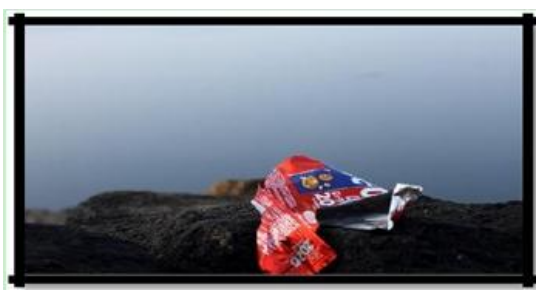

Fig. 13. Plastics are thrown near reservoir

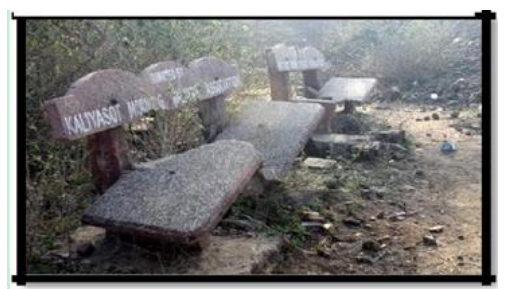

Fig. 14. Kaliasot morning walker's association

\section{PUBliCATION PRINCIPLES}

\section{A. Effects of Human Interventions}

All ecological activities are related to one another in One or the other form. Some interventions are natural and are important but on the other hand some interventions are harmful for nature [24]-[26]. There are some activities of human which are related with water but disposing waste in water is no where a good solution for discharge same is with idol immersion in historical periods idols are made of mud and hence it get easily dissolved in water but now a day's idols 
are made of plaster of Paris which is not dissolvable in water . Water bodies provide a healthy environment but humans are only responsible for destroying it by converting these places to a place of their comfort [26]. We need to be sensitive towards our environment and have to use it in proper way. The most significant among the water quality issues of the reservoir are as under:

- Silting from the catchment area

- Weakening of earthen dam

- Direct human intervention

- Idol immersion

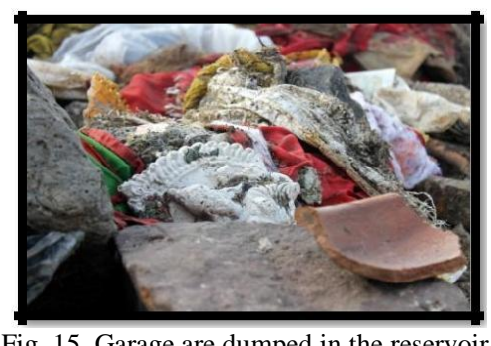

Inflow of treated nutrient rich effluent of Kotra Sewage Treatment Plant (STP). Kaliasot Reservoir, earlier, was famous for the migratory birds in Bhopal . Rapid urbanization and increasing pollution level has resulted in decrease in the number of influx of migratory birds [27]. Moreover, plants are also getting affected due to pollution level.

\section{CONCLUSION}

It is quite a well known fact that all the elements of ecosystems are inter-dependent on each other. Thus, it should be kept in mind that disturbing the natural ecological balance not only affects the plants and animals but also humans. The criteria to be used for the evaluation of landscape quality must be oriented towards the maintenance of natural functions, structure, ecological equilibrium conditioned by ecological site and natural design material and not by artificial material. In recent years, landscaping and ecology are also closely interwoven with all other interdisciplinary aspects of rural and urban planning. Hence, it can be concluded that to avoid disastrous situations the ecological balance should be strictly maintained. Moreover, urbanization and industrialization should be done in such a way that the effects on natural environment are least.

\section{REFERENCES}

[1] Z. Naveh and S. Arthur, "Landscape ecology: Theory".

[2] A. Farina, "Principles and methods in landscape ecology".

[3] R. Boonstra et al., "The impact of predator-induced stress on the snowshoe hare cycle," Ecological Monographs, vol. 79, pp. 371-394, 1998.

[4] J. S. Brown, "Patch use as an indicator of habitat preference, predation risk, and competition," Behavioral Ecology and Sociobiology, vol. 22, pp. 37-47, 1988 .
[5] S. Creel and D. Christianson, "Relationships between direct predation and risk effects," Trends in Ecology \& Evolution, vol. 23, pp. 194-201, 2008.

[6] D. A. Frank, "Evidence for top predator control of a grazing ecosystem," Oikos, vol. 117, pp. 1718-1724, 2008.

[7] J. A. Gude et al., "Prey risk allocation in a grazing ecosystem," Ecological Applications, vol. 16, pp. 285-298, 2006.

[8] L. Hernández and J. W. Laundré, "Mapping the landscape of fear and its implications to conservation efforts," presented at 8th International Theriological Congress, Sun City: South Africa, p. 71, 2001.

[9] J. W. Laundré et al., "Wolves, elk, and bison: Reestablishing the "landscape of fear," Canadian Journal of Zoology, vol. 79, pp. 1401-1409, 2001

[10] W. J. Ripple and R. L. Beschta, "Wolf reintroduction, predation risk, and cottonwood recovery in Yellowstone National Park," Forest Ecology and Management, vol. 184, pp. 299-313, 2003.

[11] S. A. Temple, "Do predators always capture substandard individuals disproportionately from prey populations?" Ecology, vol. 68, pp. 669-674, 1987.

[12] C. A. White et al., "Predation risk and the functional response of elk-aspen herbivory," Forest Ecology and Management, vol. 181, pp. 77-97, 2003.

[13] J. Wu and R. Hobbs, "Key issues and research priorities in landscape ecology: An idiosyncratic synthesis," Landscape Ecol., vol. 17, pp. 355-365, 2002.

[14] J. A. Wiens, "Allerton Park 1983: th\#e beginnings of a paradigm for landscape ecology?" Landscape Ecol., vol. 23, pp. 125-128, 2008.

[15] H. Kataria and Y. Singh, "Analysis of trace elements in water of kaliyasot dam, bhopal (India)," Journal of Environmental Research And Development, pp. 156-162, 2008.

[16] S. Malik et al., "Water quality management of water resources of Bhopal city: Challenges and scope," International Research Journal of Environment Sciences, pp. 22-26, 2014.

[17] C. D. Hargis et al., "The behavior of landscape metrics commonly used in the study of habitat fragmentation," Landscape Ecol., vol. 13, pp. 167-186, 1998.

[18] P. G. Risser et al., "Landscape ecology: directions and approaches," 1984.

[19] M. G. Turner, "Landscape ecology: The effect of pattern on process," Annu Rev Ecol Syst., vol. 20, pp. 171-197, 1989.

[20] D. E. Jelinski and J. G. Wu, "The modifiable areal unit problem and implications for landscape ecolgy," Landscape Ecol., vol. 11, pp 129-140, 1996.

[21] R. T. T. Forman and M. Godron, Landscape Ecology, New York: Wiley, 1986

[22] G. S. Dodds and F. L. Hisaw, "Ecological studies of aquatic insects. II Size of respiratory organs in relation to environmental conditions," Ecology, vol. 5, pp. 262-271, 1924.

[23] P. J. Edwards et al., "A conceptual model of vegetation dynamics on gravel bars of a large Alpine river," Wetlands Ecology and Management, vol. 7, pp. 141-153, 1999.

[24] Z. Naveh, "Biodiversity and landscape management," Biodiversity and Landscapes. A Paradox of Humanity, pp. 187-207, Cambridge: Cambridge University Press, 1994

[25] N. E. Roth, J. D. Allan, and D. L. Erickson, "Landscape influences on stream biotic integrity assessed at multiple spatial scales," Landscape Ecology, vol. 11, pp. 141-156, 1996.

[26] J. A. Wiens, "Understanding the problem of scale in experimental ecology," Scaling Relationships in Experimental Ecology, pp. 61-88, New York, USA: Columbia University Press, 2001.

[27] I. S. Zonneveld, Land Ecology, Academic Publishing, 1995.

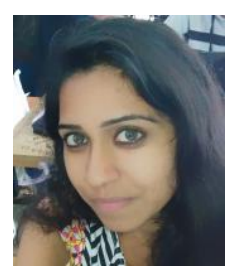

P. M. Venodha was born on October 31, 1995. She is pursuing physical planning in NIT, Bhopal. She is interested in environmental planning and transportation planning. She participated in national conference on "Sustainable Neighbourhood: Theories \& Practices" in 2014. She presented a paper entitled "Eco- tourism" in the World Ocean Science Congress in 2015 . 